\title{
Food consumption patterns, nutrient adequacy, and the food systems in Nigeria
}

\author{
Daniel A. Mekonnen ${ }^{1 *} \mathbb{D}$, Laura Trijsburg² ${ }^{2}$ Thom Achterbosch', Inge D. Brouwer ${ }^{2}$, Gina Kennedy ${ }^{3}$,
} Vincent Linderhof ${ }^{1}$, Ruerd Ruben ${ }^{4}$ and Elise F. Talsma ${ }^{2}$

* Correspondence: daniel.
mekonnen@wur.nl
${ }^{1}$ Wageningen Economic Research,
Wageningen University and
Research, Pr. Beatrixlaan 582, 2595,
BM, The Hague, The Netherlands
Full list of author information is
available at the end of the article

* Correspondence: daniel. mekonnen@wur.n Wageningen University and Research, Pr. Beatrixlaan 582, 2595, Full list of author information is available at the end of the article

\begin{abstract}
Previous studies in Nigeria examined food and nutrition security mainly using anthropometric indicators, total calorie intake, or the household dietary diversity score (HDDS). However, recent evidence on nutrient and dietary gaps, especially from nationally representative surveys, is weak. This study contributes by examining factors influencing household mean nutrient adequacy and HDDS with focus on components of food systems in Nigeria. Based on the 2015/16 Nigeria General Household Survey, we found that fruits and animal source foods were the least consumed food groups. Yet, these food groups seem to be the main sources of difference in HDDS and were strongly associated with the mean probability of nutrient adequacy, given covariates. Among 11 nutrients under study, large shortfalls were observed in consumption of iron, vitamin $B_{12}$, and riboflavin with probability of adequacy being 0.2 or below, followed by niacin, vitamin $C$, and zinc with corresponding probability of adequacy ranged between 0.48 and 0.58 . Further, results suggested that mobile phone ownership by the household head, household's access to electricity, improved sources of water for household consumption, and percent of the community with improved sanitation were strongly associated with HDDS. Heterogeneities in food groups and nutrient consumption and food system drivers are discussed.
\end{abstract}

Keywords: Nutrient adequacy, Household dietary diversity, Food systems, Nigeria

\section{Springer Open}

\section{Introduction}

Improved nutrition is thought to have a multiplier effect across the Sustainable Development Goals (SDGs) (Development Initiatives 2017). Yet, much like other low- and middle-income countries, achieving the SDGs in Nigeria is challenged by co-existence of undernutrition, micronutrient deficiencies, and growing rates of overweight and obesity in the population. Based on the 2008 Nigerian Demographic and Health Survey (NDHS), Kandala and Emina (2016) reported that the prevalence of undernutrition (underweight) and overnutrition (overweight) in women of reproductive age was $12 \%$ and $20.9 \%$, respectively. Based on the same data, Kandala and Stranges (2014) observed that the prevalence of overweight and obesity varies across ethnic groups and the state of residence in Nigeria. In

(c) The Author(s). 2021 Open Access This article is licensed under a Creative Commons Attribution 4.0 International License, which permits use, sharing, adaptation, distribution and reproduction in any medium or format, as long as you give appropriate credit to the original author(s) and the source, provide a link to the Creative Commons licence, and indicate if changes were made. The images or other third party material in this article are included in the article's Creative Commons licence, unless indicated otherwise in a credit line to the material. If material is not included in the article's Creative Commons licence and your intended use is not permitted by statutory regulation or exceeds the permitted use, you will need to obtain permission directly from the copyright holder. To view a copy of this licence, visit http://creativecommons.org/licenses/by/4.0/. 
Nigeria, high body mass index (BMI)-related deaths have increased by $29 \%$ among females and by 79\% among males between 1990 and 2015 (GBD 2015 Obesity Collaborators, 2017). These signal a "nutrition transition"-the shift in dietary consumption towards increased intake of foods high in fats, sugar, and salts (HFSS), and decreased caloric expenditure that coincides with economic, demographic, and epidemiological changes (Popkin 1993, 2015). In fact, Adegboye et al. (2016) summarized evidence of the dietary changes from "traditional" to more processed foods which has been observed in recent years in Nigeria. In general, the difference in the nutrition transition across federal states may be linked to differences in prevailing food systems, including production, processing, distribution, trade, food environments, ${ }^{1}$ and consumer behavior (HLPE 2017). This is because the food systems determine availability, affordability, convenience, and desirability of various foods. The food environment in markets, for example, constrains and signals consumers what to purchase and modifies their dietary consumption (Herforth and Ahmed 2015). This implies there is potential to nudge consumer behavior towards healthier and sustainable diets and address nutritional challenges through changes in the food systems. Identifying entry points for interventions requires understanding of the link between dietary consumption and the components of the existing food systems.

Nigeria is undergoing rapid urbanization with a rapidly growing population. It follows that the food systems in urban and rural areas may grow more distinct and so do the nutritional problems and the interventions needed to solving them. For example, urban poor are more dependent on food purchases, and the diets of urban poor are likely to be more diverse than that of the rural poor. While this may entail better access to quality food and nutrients, given purchasing power, their dependence on markets for food makes urban poor more vulnerable to prices and other market shocks (Mohiddin et al. 2012) and hence to undernutrition. In contrast, urban households tend to consume food away from home and more processed foods than rural households (de Brauw and Herskowitz 2018) and hence are more vulnerable to health risks related to consumption of foods HFSS (Kengne et al. 2017). This is because consumption of processed foods HFSS, coupled with inadequate physical activity, is found to be linked to the surge in overweight and obesity rates (FAO et al. 2017). Even though urbanization is generally seen as the engine of growth and development, it may also lead to urban health crises when not managed carefully. Evidence shows that urbanization in Nigeria has created urban health crises of "inadequate safe water supply, squalor and shanty settlements, sanitation, solid waste management, double burden of diseases and inefficient, congested, and risky transport system" (Aliyu and Amadu 2017, p.149). Hence, food safety is compromised in such circumstances. The complexity in food systems, for example due to urbanization, implies that any attempt at improving the multiple burden of malnutrition would require a systemic approach to identifying risk factors and designing evidence-informed policies and interventions that account for spatial and socio-cultural issues.

${ }^{1}$ The food environment is defined as the physical, economic, political, and sociocultural context in which consumers engage with the food system to make their decisions about acquiring, preparing, and consuming food (HLPE 2017, p.28). 
Previous studies in Nigeria attempted to establish a statistical association between food and nutrition security (mainly using anthropometric indicators, total calorie intake, or household dietary diversity) and potential determinants (e.g., Kandala and Stranges 2014; Babatunde and Qaim 2010; and Ecker et al. 2018). Yet, these studies did so without examining the magnitude of nutrient and dietary gaps and not necessarily using the food system perspective (for example, these studies did not link nutrient and dietary gaps and components of food systems such as access to/use of irrigation, mobile phone, electricity, water, health care, and markets). Further, these studies were drawn from samples which were not nationally representative. On the other hand, based on the rural subset of the 2010-2011 Nigeria General Living Standards Measurement Surveys (LSMS-ISA), dietary profiles and statistical association between household dietary diversity and the likelihood of adequate consumption of nutrients were established (Akerele et al. 2017). Relatedly, based on a country-wide sample survey from 2003/ 2004, evidence suggests that greater burden of nutritional deficiencies was borne by lowincome household cohorts, and deficiency of micronutrients was diffused across urban-rural divides with deficiency of calcium, vitamin $\mathrm{A}$, and vitamin $\mathrm{C}$ appearing to be more pronounced in rural areas while phosphorous, vitamin $B_{1}$, vitamin $B_{2}$, and vitamin $B_{3}$ deficiencies seem to be higher in urban settings (Akerele 2015).

While existing studies and especially Akerele (2015) offer important insight to understanding nutrient and dietary gaps in Nigeria, the food systems and consumption patterns may have changed since 2003/2004 when the data used by Akerele (2015) was collected. In addition, the study estimated nutrient contents from food consumption expenditure data, not directly reflecting food consumption. Also, price data for 38 out of 133 food commodities were extrapolated from "close substitutes." This may further introduce measurement error even though Akerele (2015) noted that these commodities were "not dominant sources of nutrients" and only "account for $7 \%$ of total household food budget."

Previous studies suggested that nutrition-sensitive, food-based approaches towards multiple forms of malnutrition are effective, sustainable, and long-term solutions (Thompson and Amoroso 2014). Strategies may involve improving the quality and diversity of the diet through increasing availability and access to the foods necessary for a healthy diet, and increasing the actual consumption of those foods. Hence, the main objective of this study was to identify entry points for interventions in the existing food systems in Nigeria. This was done in three steps. First, patterns of food group consumption and household nutrient adequacy by rural and urban divides were explored. Second, the link between the average nutrient adequacy and food group consumption was examined. Finally, factors influencing household dietary diversity with focus on some components of food systems in Nigeria were examined. The remainder of this study is structured as follows: the next section presents the conceptual framework that guides the study. Method of analysis and data is described in the "Methods" section. The "Results" section presents econometric results and discussions, and the "Conclusions" section concludes.

\section{Conceptual framework}

The change in the food systems is likely to create new nutritional challenges while opening opportunities. To unravel this complexity and identify entry points for interventions, this study adapts the conceptual framework of food systems for diets and 
nutrition by the High Level Panel of Experts for Food Security and Nutrition (HLPE 2017). The key interactions that determine diets are summarized in Fig. 1. According to this framework, diets are shaped by the interactions of food supply chains, food environments, and consumer behavior. Production, storage, distribution, processing and packaging, retail, and markets are activities that comprise the food supply chain. Many actors are involved along the supply chains, and their involvement may improve nutritional value of food (e.g., fortification) and in some cases reduce nutritional value of food due to losses or contamination (HLPE 2017). The actions of these actors may also affect the food environment-which comprises of food availability and physical and economic access to food, promotion, advertising and information, and food quality and safety (HLPE 2017). As noted before, the food environment in turn affects consumer choices and decisions including what food to acquire, store, prepare, cook, and eat. This is because, beside personal preferences, food prices, income, knowledge and skills, time and equipment, and social and cultural norms are some of the determinants of food choices (HLPE 2017) with implications on nutrient acquisition. In this regard, Adegboye et al. (2016) discussed differences in nutrient acquisition corresponding to three cultural food customs from southwest, eastern, and northern Nigeria.

Interactions between components of the food systems determine diets-quantity, quality, diversity, and safety. Nonetheless, dietary patterns may also act as drivers of change for future food systems (HLPE 2017). This is because diets affect nutrition and health outcomes and have social, economic, and environmental impacts. This and growing demand for food would necessitate sustainability in production, consumption, and enabling conditions such as future regarding behavior by the food systems actors. These interlinkages may affect the food systems directly through political or

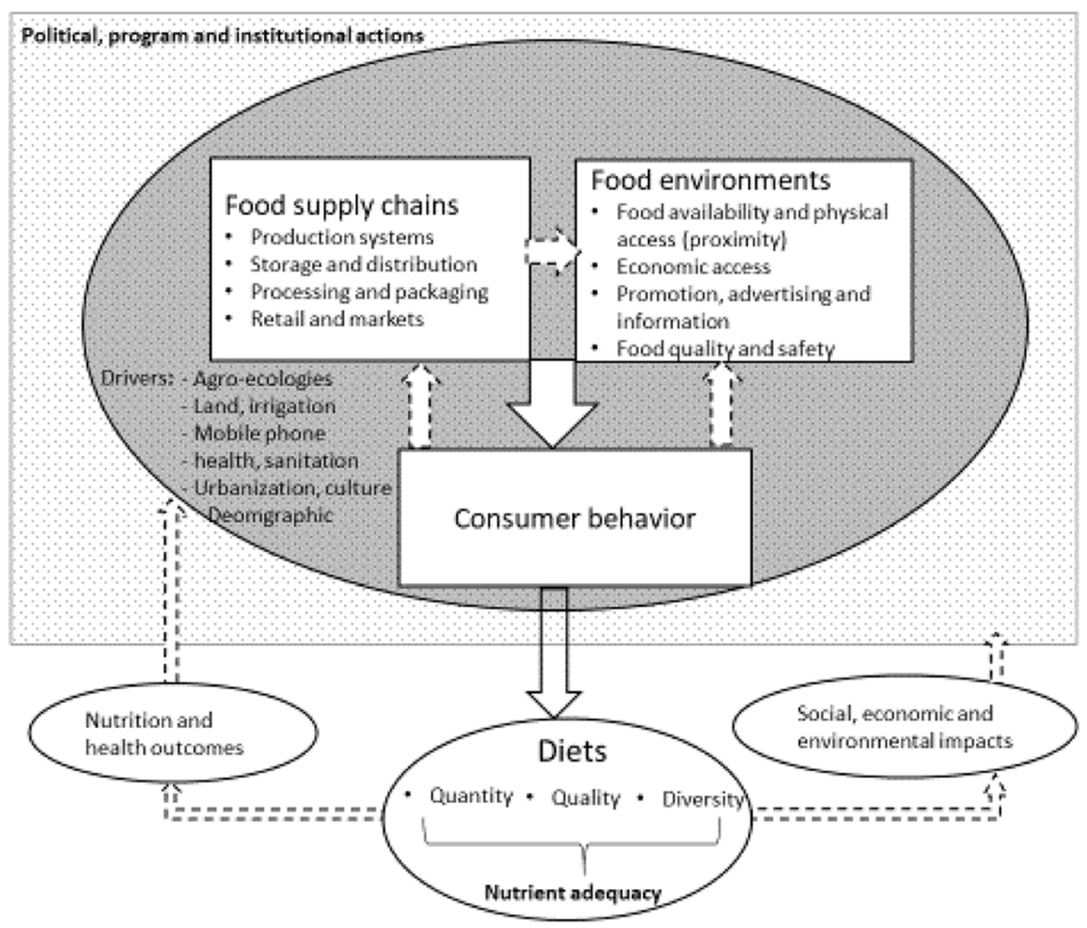

Fig. 1 Conceptual framework of food systems for diets and nutrition. Adapted from HLPE (2017) 
institutional actions or indirectly by influencing the drivers of the food systems including biophysical and environmental, innovation, technology and infrastructure, political and economic, socio-cultural, and demographic drivers (HLPE 2017). Our interest in this study is to examine the influence of food system components on nutrient and dietary gaps, depicted by solid arrows of Fig. 1.

\section{Methods}

Data

A lack of food consumption surveys specifically designed for food and nutrition research from representative samples remain a major constraint to studying nutrient and dietary gaps in Nigeria. However, the General Living Standards Measurement Surveys (LSMSISA) offer a useful alternative. It provides information on quantity of food items consumed in the household over 7 days, by food source including own production, purchases, and other sources. The LSMS-ISA Nigeria is panel data collected by the National Bureau of Statistics of Nigeria in conjunction with its partners (NBS et al. 2016). To date, three waves of data, collected in 2010-2011, 2012-2013, and 2015-2016, for both pre-harvest and post-harvest seasons, are available. One of the main advantages is that the LSMS-ISA sample is large in size with about 5000 households at baseline and is representative of all 36 states in Nigeria, and it is a rich source of information from the food system perspective as food consumption data can be linked to different aspects of the food systems. For example, data on certain driving forces of consumption such as proximity of food markets may allow to gain more insight into the linkages in the food system dynamics. Our interest was to examine the state of nutrient and diet gaps, based on recent data. Hence, this study used the 2015-2016 post-harvest wave which has information on food consumption of 4570 households. Data were prepared according to the following steps: (1) local units were converted into grams, kilograms, or liters of the food item consumed; (2) using the price, cost, and unit data per food item, data were checked for extreme values of food item consumption. Data were checked on whether the quantity of total consumption for each food item was equal to the sum of quantities consumed from own stock, from purchases, and gifts, and whether the reported consumption expenditure was consistent with prices per unit of the food item; (3) observations outside the plausible consumption range of 500-5000 kcal consumption per person per day (Voortman et al. 2017) were excluded resulting in 528 exclusions. After these data checks, the sample size used in this study came to 4042 households.

Nutrient consumption was calculated in terms of adult female equivalent (AFE). The AFE allows for a division of the household food and nutrient consumption to an individual household members' consumption as a proportion of energy requirements of an adult women (20-30 year). All other age and gender groups received an AFE value by dividing their energy requirement by the energy requirement of 1 AFE. For each household, the household AFE was calculated by summing up the AFEs of individual household members. The LSMS-ISA survey questionnaire does not define edible portions of food items. We assumed that respondents report consumption of the non-treated, nonprepared product. Waste factors (refuse factors) (US Department of Agriculture, Agricultural Research Service (USDA) 2016) were thus applied to the food items before further analysis. For some foods, no waste factors were available so imputations were 
made using similar foods. The energy and nutrient intake of the household were calculated using the FCT data from Langenhoven et al. (1991), West et al. (1989), and US Department of Agriculture, Agricultural Research Service (USDA) (2016). To account for changes in energy and nutrient content due to processing and cooking of food items, retention factors were applied (US Department of Agriculture, Agricultural Research Service (USDA) Nutrient Data Lab 2017).

\section{Data analysis}

The prevalence of nutrient adequacy was calculated using the probability approach ${ }^{2}$. The probability approach makes use of the estimated average requirements (EARs), which is the daily nutrient intake value estimated to meet the requirements of half of the healthy individuals in a given population (Institute of Medicine (IOM) 2006). Assuming normal distribution ${ }^{3}$ and nutrient requirement of adult women, the standardized score ( $z$-score) of adequacy for nutrient $j$ was calculated as:

$$
\begin{gathered}
\mathrm{z}_{j}=\frac{\text { usual intake }_{j}-\mathrm{EAR}_{j}}{\mathrm{SD}_{j}} \\
\mathrm{SD}_{j}=\mathrm{CV}_{j} \times \mathrm{EAR}_{j}
\end{gathered}
$$

where $\mathrm{SD}_{j}$ and $\mathrm{CV}_{j}$ respectively represent the standard deviation and coefficient of variation for nutrient $j$. The usual intake was replaced by estimated daily nutrient consumption per $\mathrm{AFE}$ as described earlier. The $\mathrm{EAR}_{j}$ and $\mathrm{SD}_{j}$ values corresponding to the European Food Safety Authority (EFSA, 2017) intake recommendations for non-pregnant and non-lactating adult women were obtained from EFSA (2017) and World Health Organization and Food and Agriculture Organization of the United Nations (WHO/FAO) (2004), respectively. Using standardized $z$-scores and the property of standard normal distribution, the probability of adequacy for each nutrient was computed. Finally, the mean probability of adequacy (MPA) was calculated by averaging the probability of adequacy of 11 nutrients including iron, calcium, zinc, thiamin, riboflavin, niacin, vitamin $\mathrm{B}_{6}$, folate, vitamin $B_{12}$, vitamin $C$, and vitamin $A$. The MPA is a summary measure of adequacy of nutrient consumption (formula for construction of MPA is in the Appendix).

The household dietary diversity was assessed using the household dietary diversity score (HDDS), a composite measure and proxy for household's average food access (Swindale and Bilinsky 2006). The HDDS was calculated based on whether anyone in the household consumed any food from the 12 food groups during the recall period ( 7 days in this analysis). The food groups (FG) include the following: cereals; white roots and tubers; vegetables; fruits; meat and poultry; eggs; fish and other sea food; pulses, nuts, and seeds; milk and milk products; oils and fats; sweets; spices, condiments, and beverages.

To examine the link between consumption of the food groups (FG) and the mean probability of adequacy (MPA), the following empirical model was estimated:

\footnotetext{
${ }^{2}$ The probability of adequacy (PA) method is generally applied to quantitative 24-h recall data on dietary intake of one individual and needs to be repeated on at least a sub sample of subjects in order to estimate interand intraindividual variation in nutrient intake. Hence, due to substantial deviation from the recommended methodology, the PA values calculated using LSMS data could be treated as at best "estimates of PA." ${ }^{3}$ The requirements for iron are known to be skewed for non-pregnant and non-lactating women (see IOM, 2006 pp.43-44). Hence, we calculate the prevalence of (in)adequacy for iron per adult women using the probability of adequacy table (see Wiesmann et al. 2009, p.206, adapted from IOM, 2006). We refer to the probability of adequacy which adjusts for a bioavailability of $5 \%$.
} 


$$
M P A_{i}=F G_{i} \boldsymbol{\alpha}+\boldsymbol{x}_{\boldsymbol{i}} \boldsymbol{\beta}+F S_{i} \boldsymbol{\pi}+\boldsymbol{S}_{\boldsymbol{i}} \boldsymbol{\delta}+\mu_{i}+\mathrm{t} T_{i}+e_{i}
$$

where $\boldsymbol{x}_{i}$ denotes a vector of household $i$ 's observable characteristics including age, gender, and education attainment of the household head, the household size (in AFE), dependency ratio, income quintile indicator, and ratio of expenditure on meal away from home (MAH) to expenditure on food at home. $F S_{i}$ denotes a vector of some indicators of food systems (including access to mobile phone, electricity, improved source of water for household consumption, improved sanitation (at level of community), irrigation, distance to market, distance to nearest town with $20,000+$ people, dummy for availability of health center/hospital in the community, the percent of agriculture within approximately $1 \mathrm{~km}$, and dummies for agroecological zones). $\mu_{i}$ is a dummy whether place of household is rural or urban and $S_{i}$ denotes a set of state-fixed effects. These geographic fixed effects control for unobservable characteristics including food prices and institutional and cultural factors that do not vary within states but may influence food and nutrient consumption; $T_{i}$ denotes month of interview fixed effects (such as difference in food prices over time), and $e_{i}$ is an error term. $\boldsymbol{\alpha}, \boldsymbol{\beta}, \boldsymbol{\pi}, \boldsymbol{\delta}, \mu$, and are coefficients to be estimated. Our interest was the estimates of $\boldsymbol{\alpha}$. The food systems in rural areas might be different from those of urban, with implications on food consumption and the average nutrient adequacy. Hence, variants of Eq. 2 were estimated, separately for rural and urban households after excluding $\mu_{i}$.

Similarly, correlates of household dietary diversity score (HDDS) were examined with focus on some components of the food systems by estimating the following model:

$$
H D D S_{i}=\boldsymbol{x}_{\boldsymbol{i}} \boldsymbol{\beta}+F S_{i} \boldsymbol{\pi}+\boldsymbol{S}_{\boldsymbol{i}} \boldsymbol{\delta}+\mu_{i}+\mathrm{t} T_{i}+\sigma_{i}
$$

where $\boldsymbol{x}_{i}, F S_{i}, S_{i}, \mu_{i}$, and $T_{i}$ are as defined before, and $\sigma_{i}$ represents the error term. Our interest was the estimates of $\boldsymbol{\pi}$. As before, variants of Eq. 3 were estimated, separately for rural and urban households after excluding $\mu_{i}$.

\section{Descriptive statistics}

Table 1 presents the general overview of sample households on their socio-economic and demographic characteristics. About 67\% of households were from rural areas. Among rural households, about $83 \%$ of them were male headed while the corresponding figure for urban counterparts was $77 \%$. The average age of the household head was about 52 years in both rural and urban areas. The share of household heads with post-primary level of education in urban areas was about 56\%. This is nearly twice that of corresponding share in rural areas. The average household size in female adult equivalent was about 6 in rural areas, which is higher by 1 AFE than that of urban counterparts. In terms of access to utilities and services including mobile phone, electricity, improved water source and sanitation, and health services, the shares of households with access were higher in urban areas than that of corresponding shares of rural counterparts. The ratio of expenditure on meal away from home (MAH) to expenditure on food at home was 0.35 and 0.6 in rural and urban households, respectively. The data also suggests households in urban areas were in closer proximity to large weekly markets and larger population centers than households in rural areas. The percent of land under agriculture within approximately $1 \mathrm{~km}$ buffer of household's location was on average 33\% and $15 \%$ in rural and urban areas, respectively. 
Table 1 Descriptive statistics of key variables used in the regressions ( $N=4042$ )

\begin{tabular}{|c|c|c|c|c|c|c|c|c|}
\hline & \multicolumn{2}{|c|}{$\begin{array}{l}\text { Country } \\
(n=4042)\end{array}$} & \multicolumn{2}{|c|}{$\begin{array}{l}\text { Rural } \\
(n=2721)\end{array}$} & \multicolumn{2}{|c|}{$\begin{array}{l}\text { Urban } \\
(n=1321)\end{array}$} & \multicolumn{2}{|c|}{$\begin{array}{l}\text { Diff.=urban } \\
\text {-rural }(t \text {-test) }\end{array}$} \\
\hline & Mean & S.D. & Mean & S.D. & Mean & S.D. & Diff. & t-stat. \\
\hline Household head is male $(1 / 0)^{a}$ & 0.81 & 0.39 & 0.83 & 0.37 & 0.77 & 0.42 & -0.06 & $-4.47^{* *}$ \\
\hline Age of household head in years & 52.4 & 14.2 & 52.4 & 14.3 & 52.4 & 14.1 & -0.06 & -0.13 \\
\hline $\begin{array}{l}\text { Household head attained post-primary } \\
\text { education }(1 / 0)\end{array}$ & 0.38 & 0.48 & 0.29 & 0.45 & 0.56 & 0.50 & 0.27 & $16.9^{* *}$ \\
\hline Household size in adult female equivalent & 5.53 & 3.03 & 5.82 & 3.08 & 4.91 & 2.82 & -0.91 & $-9.07^{* *}$ \\
\hline Dependency ratio (share of children $<14$ and adults $>64$ ) & 0.42 & 0.25 & 0.44 & 0.24 & 0.39 & 0.26 & -0.04 & $-5.21^{* *}$ \\
\hline \multicolumn{9}{|l|}{ Household expenditure quintile } \\
\hline _1 (bottom 20\%) (1/0) & 0.21 & 0.41 & 0.29 & 0.46 & 0.04 & 0.19 & -0.25 & $-19.49^{* *}$ \\
\hline $2(1 / 0)$ & 0.21 & 0.41 & 0.25 & 0.43 & 0.14 & 0.34 & -0.11 & $-7.98^{* *}$ \\
\hline$-3(1 / 0)$ & 0.20 & 0.40 & 0.20 & 0.40 & 0.22 & 0.41 & 0.02 & 1.47 \\
\hline$-4(1 / 0)$ & 0.20 & 0.40 & 0.16 & 0.37 & 0.28 & 0.45 & 0.12 & $9.12^{* *}$ \\
\hline _5 (top 20\%) (1/0) & 0.18 & 0.38 & 0.10 & 0.31 & 0.33 & 0.47 & 0.22 & $18.06^{* *}$ \\
\hline Expenditure on MAH over food at home & 0.43 & 1.61 & 0.35 & 1.00 & 0.60 & 2.41 & 0.25 & $4.73^{* *}$ \\
\hline Head own mobile phone $(1 / 0)$ & 0.73 & 0.44 & 0.65 & 0.48 & 0.90 & 0.30 & 0.24 & $17.22^{* *}$ \\
\hline $\begin{array}{l}\mathrm{HH} \text { is connected to public electricity system } \\
(1 / 0)\end{array}$ & 0.54 & 0.50 & 0.40 & 0.49 & 0.84 & 0.37 & 0.44 & $28.98^{* *}$ \\
\hline $\mathrm{HH}$ has improved water source $(1 / 0)$ & 0.52 & 0.50 & 0.46 & 0.50 & 0.66 & 0.48 & 0.19 & $12.12^{* *}$ \\
\hline Improved sanitation (toilet facility), community (\%) & 0.59 & 0.35 & 0.49 & 0.34 & 0.81 & 0.27 & 0.32 & $0.30^{* *}$ \\
\hline Health center/hospital in the community $(1 / 0)$ & 0.73 & 0.44 & 0.69 & 0.46 & 0.81 & 0.39 & 0.12 & $8.15^{* *}$ \\
\hline $\mathrm{HH}$ has irrigated plot $(1 / 0)$ & 0.01 & 0.12 & 0.02 & 0.13 & 0.01 & 0.09 & -0.01 & $-2.17^{* *}$ \\
\hline HH distance to nearest large weekly market (km) & 67.76 & 43.92 & 71.30 & 39.50 & 60.45 & 51.12 & -10.85 & $-7.41^{* *}$ \\
\hline $\begin{array}{l}\mathrm{HH} \text { distance in }(\mathrm{km}) \text { to nearest population center with }+20 \text {, } \\
000(\mathrm{~km})\end{array}$ & 23.65 & 20.07 & 29.08 & 20.26 & 12.47 & 14.19 & -16.60 & $-26.76^{* *}$ \\
\hline Fraction of land under agriculture within $1 \mathrm{~km}$ buffer & 27.78 & 27.00 & 33.66 & 27.37 & 15.68 & 21.69 & -17.98 & $-20.90^{* *}$ \\
\hline \multicolumn{9}{|l|}{ Agroecological zones } \\
\hline Tropic-warm/semiarid (1/0) & 0.30 & 0.46 & 0.37 & 0.48 & 0.16 & 0.37 & -0.20 & $-13.79^{* *}$ \\
\hline Tropic-warm/subhumid (1/0) & 0.57 & 0.49 & 0.51 & 0.50 & 0.71 & 0.45 & 0.20 & $12.38^{* *}$ \\
\hline Tropic-warm/humid (1/0) & 0.12 & 0.32 & 0.12 & 0.32 & 0.12 & 0.33 & 0.01 & 0.70 \\
\hline Tropic-cool/sub-humid (1/0) & 0.01 & 0.10 & 0.01 & 0.10 & 0.01 & 0.09 & -0.00 & -0.74 \\
\hline \multicolumn{9}{|l|}{ Month of interview } \\
\hline February $(1 / 0)$ & 0.28 & 0.45 & 0.25 & 0.43 & 0.34 & 0.47 & 0.08 & $5.74^{* *}$ \\
\hline March (1/0) & 0.71 & 0.45 & 0.74 & 0.44 & 0.64 & 0.48 & -0.09 & $-6.41^{* *}$ \\
\hline April (1/0) & 0.01 & 0.12 & 0.01 & 0.10 & 0.02 & 0.15 & 0.01 & $2.84^{*}$ \\
\hline
\end{tabular}

${ }^{a}(1 / 0)$ denotes dummy variable and s.d. denotes standard deviation

${ }^{* *} p<0.01,{ }^{*} p<0.05$

\section{Household Dietary Diversity Score (HDDS) and consumption patterns}

The mean HDDS of households was 8.7 (s.d. 1.9), with corresponding values for rural and urban households being 8.4 (1.9) and 9.4 (1.8), respectively. ${ }^{4}$ The HDDS however does not reveal household heterogeneities regarding type of food groups consumed and the share of households consuming. According to Fig. 2, fruits and nutrient-dense animal source foods (ASF) were consumed the least. For example, eggs and milk and milk products were consumed by less than $40 \%$ of households while fruits and meat were

${ }^{4}$ Note that the higher value of HDDS observed in this study was due to the use of 7-day recall as opposed to the conventional 24-h recall used to calculate dietary diversity; a longer data recording leads to higher HDDS scores 


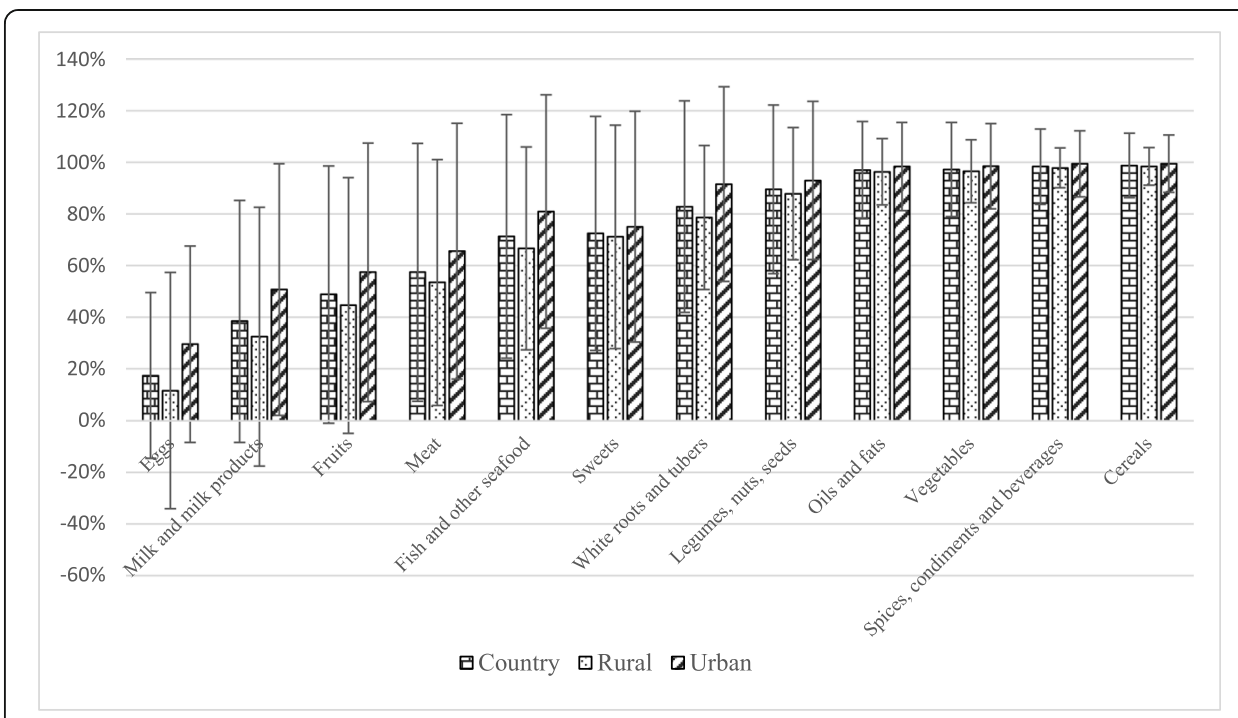

Note: Error bars represent standard deviations. Percentage mean difference for each food group between rural and urban households was statistically significant at $\mathrm{p}<0.05$

Fig. 2 Share of households consuming food group (\%)

consumed by less than $60 \%$ of households, on average. However, the share of households consuming each of these food groups was greater in urban areas than that of rural areas. Cereals, spices and condiments, vegetables, and oils and fats were consumed by nearly all households. In general, the main differences in household dietary diversity seem to be driven by consumption of fruits and ASF (Fig. 2).

\section{Household nutrient consumption and gap}

Figure 3 summarizes the probability of adequacy of nutrient consumption and corresponding gap for 11 nutrients and the mean probability of nutrient adequacy (MPA). According to Fig. 3, there were large shortfalls in consumption especially of three nutrients including iron, vitamin $\mathrm{B}_{12}$, and riboflavin. The probability of nutrient adequacy (PA) for each of these three nutrients was 0.2 or below, regardless of location of residence. In contrast, nutrients with higher probability of adequacy (i.e., PA between 0.8 and 0.95 ) include thiamine, vitamin A, vitamin $\mathrm{B}_{6}$, and folate, in both rural and urban areas. Other nutrients including zinc, vitamin $C$, and niacin had a probability of adequacy between 0.43 and 0.79 . The MPA for urban and rural households was 0.54 (s.d. 0.22 ) and 0.58 (s.d. 0.22 ), respectively.

\section{Results}

\section{The link between average nutrient adequacy and food group consumption}

Descriptive statistics in Fig. 2 showed that cereals, spices and condiments, vegetables, and oils and fats were consumed by nearly all households, regardless of the household's location being a rural or urban area. In contrast, consumption patterns of fruits and animal source foods were slightly higher in urban areas. These consumption patterns are based on whether or not a food group is consumed, however, may not give 


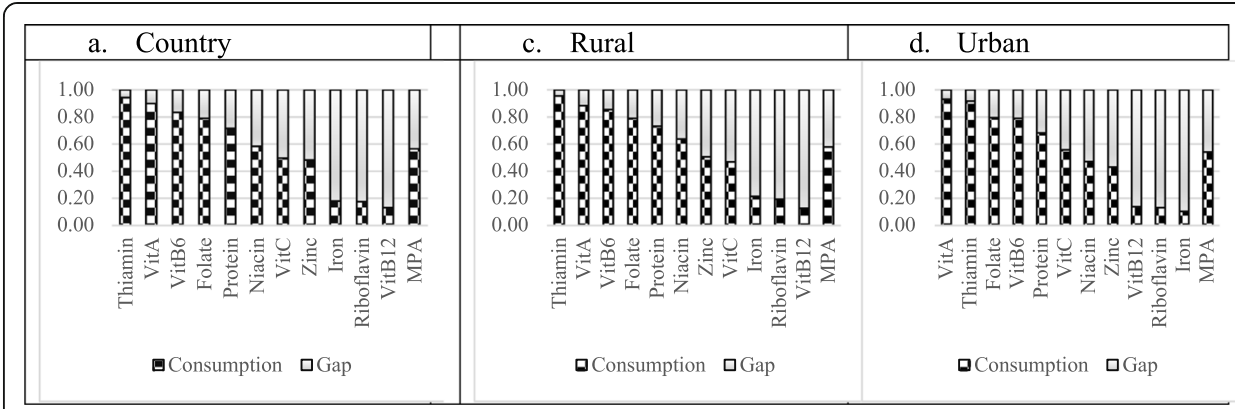

Note: With the exception of vitamin $\mathrm{B}_{12}$ and folate, the mean difference in the probability of adequacy of each nutrient consumption between rural and urban households was statistically significant at $\mathrm{p}<0.05$.

Fig. 3 Household (per AFE) nutrient consumption and gap

sufficient information about the link between food group consumption and the average nutrient adequacy. This is because nutrient content of each of these food groups and of foods within each food group is different, and portion size or amount consumed and other factors also play a role in determining household's mean probability of nutrient adequacy (MPA). Accordingly, after controlling for cultural, economic, and food environment factors ${ }^{5}$, results on country level suggest that each of the food groups with the exception of cereals, eggs, and spices and condiments was significantly associated with household MPA (Fig. 4). Consumption of legumes, oils and fats, and vegetables was associated with $20 \%, 15 \%$, and $13 \%$ increase in household MPA, respectively. Corresponding change in MPA associated with consumption of white roots and tubers, meat, fruits, fish and other sea food, milk and milk products, and sweets was between $3 \%$ and $10 \%$. Some of these results are in line with De Moura et al. (2016) who found a strong link between adequacy in micronutrients and consumption of red palm oil and dark green leafy vegetables in Akwa Ibom, Nigeria. For example, De Moura et al. (2016) reported that these two food groups were the main sources of vitamin A in the diet, with red palm oil and green leafy vegetables respectively contributing $50-60 \%$ and 20 $30 \%$ of vitamin A intake. Further, the aforementioned study also found that less than $10 \%$ of vitamin A intake originated from dairy products, legumes, and meat. Yet, it is to be noted that the relationship between MPA and food groups is through individual nutrients that make up the MPA.

Some of the associations between household MPA and food group consumption of the country level sample did not hold when data were disaggregated by urban and rural. For example, results showed that cereals were in fact strongly associated with household MPA for rural households. On the other hand, oils and fats, white roots and tubers, and milk and milk products were not significantly related to household MPA for urban households. Despite being consumed by a relatively smaller share of households, fruits and animal source foods (ASF) such as

\footnotetext{
${ }^{5}$ Note: see Annex Table 3 for full results. Controls include state and month of interview fixed effects; dummies for agroecological zones; share of agriculture in $1 \mathrm{~km}$ of residence; distance to nearest population center; age, sex, and education of the household head (post-primary dummy); household size; dependency ratio; ratio of expenditure on meals away from home to expenditure on food at home; dummy for $\mathrm{HH}$ income quintile; household access to services and utilities including mobile phone, electricity, improved water and sanitation, health services, and distance to market; and dummy for rural/urban for country specification.
} 


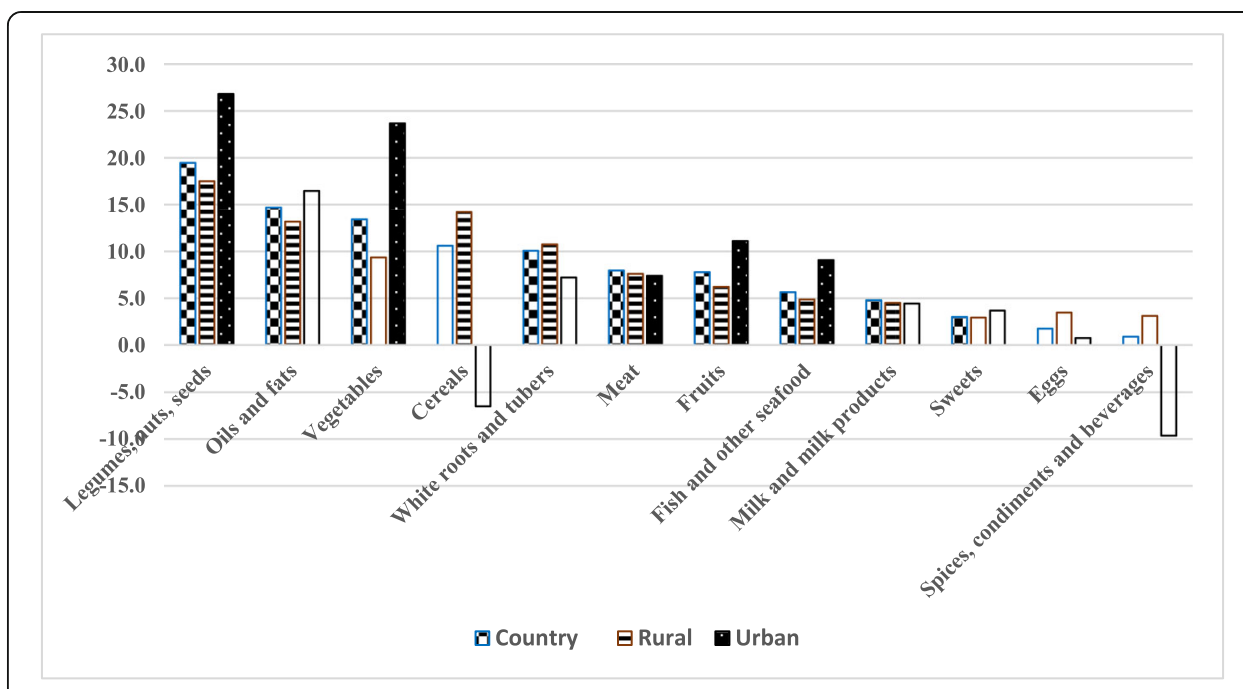

Note: Bars with fill indicate association is significant at $5 \%$ level.

Fig. 4 Percent change in MPA associated with consumption of food group, given other covariates

meat and fish and other sea food were strongly associated with household MPA for both rural and urban households. This reflects the relative importance of nutrient-rich foods including fruits and ASF for the MPA, with strong implications for nutrition outcomes. This is because a previous study found strong associations between ASF consumption and a predicted decline in child stunting, based on data from 49 countries (Heady et al. 2018). Relatedly, based on global data, a research found a positive association between the relative caloric prices of ASF and stunting in early childhood (Heady and Alderman 2019). Among food groups, the relative increase in household MPA associated with consumption of legumes and nuts, and seeds seem to be higher, regardless of location of residence. Sweets, eggs, spices, condiments, and beverages did not seem to be strongly associated with household MPA for either rural or urban households, potentially signaling a lack of diversity within each food group.

Among covariates, household size was negatively associated with household MPA whereas household income profile, age of household head, dependency ratio of household, household's location being rural, and percent of agriculture within $1 \mathrm{~km}$ were positively associated with household MPA. Further disaggregation of the data reveals that the ratio of household expenditure on meal away from home over food at home, distance to market, and access to public source of electricity was negatively associated with household MPA for the rural sample (see Appendix, Table 3).

\section{Associations between household dietary diversity and some components of food} systems

Earlier studies documented positive associations between dietary diversity and nutrient adequacy and nutrition outcomes (for reviews see Ruel 2003, and Ruel et al. 2018). Some of the avenues to improving dietary diversity may include improving access to market and roads while also providing nutrition knowledge (Stifel and Minten 2017; Hirvonen et al. 2017; Hirvonen 2016), improving incomes and production diversity (Ecker et al, 2018), and/or more generally through nutrition-sensitive agriculture programs which incorporate nutrition-related behavioral change communication (for a review, see Ruel et al. 2018, Ruel 2019). The 
effectiveness of any of these strategies however may vary across different contexts. For example, based on a meta-analysis of existing studies, Sibhatu and Qaim (2018) indicated that increasing production diversity was not a universally applicable tool to improve diets and nutrition, as some of the evidence showed production diversity was much more important in areas where access to markets was limited. These suggest that improving diets in the population may rely on several components of the food systems and require context-specific strategies. This section examines correlates of household dietary diversity with focus on some components of the food systems. It is to be noted that these results, based on analysis of cross-sectional data, are only suggestive and contributes to hypothesis generation for further research.

According to Table 2, mobile phone ownership by household head was associated with a $2.3-2.6 \%{ }^{6}$ increase in HDDS by contrast to those who did not own one, given other factors. This is because having mobile phone possibly enhances access to nutrition and other information which may help shape consumer behavior (Barnett et al. 2016). However, having access to mobile phone did not seem to be important for urban households. This is possibly because, as shown in Table 1, urban households were relatively in closer proximity to large weekly markets and larger population centers. This may increase means of receiving information and influence consumption behavior as households would have more interactions with more actors in the food value chains. Hence, the relative importance of mobile phones as means of obtaining information may be lower in such context.

Electricity has multiple uses in homes. In the context of food, it avails energy for cooking and refrigeration facilities that may help increase food shelf life, including cooked and non-cooked perishable products. This in turn may help increase food availability at home and hence household dietary diversity. Results suggest that having access to (public source of) electricity was associated with about $2 \%$ increase in HDDS, especially by urban households. Similarly, having access to improved sources of water and improved sanitation may lead to a better food environment, both at home and outside of home. For example, water can be used for cleaning and keeping food safety and for food preparation, among others. This is likely to improve consumption behavior (e.g., cleanliness of home food environment may incentivize to keeping food stocks and food preparation at home) which in turn may improve household dietary diversity. Hence, according to Table 2, having access to improved sources of water was associated with between 1.4 and $2.6 \%$ increase in household dietary diversity. In this study, improved sanitation was defined as the share of households with improved toilet facilities in the community, following Spears (2013). Sanitation improves the community and home food environment, and Spears (2013) found strong associations between differences in average child height and community level sanitation in the developing world. Our results suggest that a unit increase in the share of improved sanitation in the community was associated with a 2.6 to $4 \%$ increase in household dietary diversity, with associations being particularly stronger in rural areas.

Irrigation minimizes downside risk in food production and contributes to production diversity through reduced seasonality. This may improve availability of nutritious foods

${ }^{6}$ The mean HDDS for rural, urban, and country was 8.4, 9.4, and 8.7, respectively (Table 1 ) whereas the mean values for correlates of HDDS can be found in Table 2, for mobile phone ownership they are 0.19 , 0.24 , and 0.2 for rural, urban, and country, respectively. Hence, the percent increase in HDDS associated with mobile phone ownership was $(0.19 / 8.4) \times 100=2.3$ for rural, $(0.24 / 9.4) \times 100=2.6$ for urban, and $(0.2 /$ $8.7) \times 100=2.3$ for country. 
Table 2 Correlates of household dietary diversity

\begin{tabular}{|c|c|c|c|}
\hline & Country & Rural & Urban \\
\hline \multirow[t]{2}{*}{ Mobile phone $(0 / 1)$} & $0.20^{* * *}$ & $0.19^{* * *}$ & 0.24 \\
\hline & $(0.06)$ & $(0.06)$ & $(0.15)$ \\
\hline \multirow[t]{2}{*}{ Electricity $(0 / 1)$} & $0.13^{* *}$ & 0.12 & $0.20^{*}$ \\
\hline & $(0.06)$ & $(0.07)$ & $(0.12)$ \\
\hline \multirow[t]{2}{*}{ Improved sources of water (1/0) } & $0.12^{*}$ & 0.06 & $0.24^{* *}$ \\
\hline & $(0.06)$ & $(0.07)$ & $(0.10)$ \\
\hline \multirow[t]{2}{*}{ Irrigation (0/1) } & 0.17 & $0.36^{*}$ & -0.31 \\
\hline & $(0.20)$ & $(0.20)$ & $(0.28)$ \\
\hline \multirow[t]{2}{*}{ Improved sanitation, community (\%) } & $0.23^{* *}$ & $0.33^{* * *}$ & 0.02 \\
\hline & $(0.10)$ & $(0.11)$ & $(0.16)$ \\
\hline \multirow[t]{2}{*}{ Health center/hospital in community $(0 / 1)$} & $-0.11^{* *}$ & -0.08 & $-0.15^{* *}$ \\
\hline & $(0.05)$ & $(0.07)$ & $(0.07)$ \\
\hline \multirow[t]{2}{*}{ Distance to nearest market (KMs) } & 0.00 & 0.00 & 0.00 \\
\hline & $(0.00)$ & $(0.00)$ & $(0.00)$ \\
\hline \multirow[t]{2}{*}{ Fraction of agriculture within $1 \mathrm{~km}$ buffer $^{a}$} & $0.23^{*}$ & $0.30^{*}$ & 0.15 \\
\hline & $(0.13)$ & $(0.17)$ & $(0.28)$ \\
\hline \multirow[t]{2}{*}{ Constant } & $6.91^{* * *}$ & $6.77^{* * *}$ & $7.21^{* * *}$ \\
\hline & $(0.31)$ & $(0.32)$ & $(0.62)$ \\
\hline Observations & 4040 & 2721 & 1319 \\
\hline$r^{2}$ & 0.50 & 0.52 & 0.38 \\
\hline
\end{tabular}

Controls include state and month of interview fixed effects; dummies for agro-ecological zones; distance to nearest population center; age, sex, and education of the household head (post-primary dummy); household size; dependency ratio; ratio of expenditure on $\mathrm{MAH}$ to expenditure on food at home; dummy for $\mathrm{HH}$ income quintile; and dummy for rural/urban for country specification. Note: standard errors clustered at enumeration area-level and presented in brackets ${ }^{\text {a }}$ The variable was rescaled by dividing by 100 for readability

${ }^{* * *} p<0.01,{ }^{* *} p<0.05,{ }^{*} p<0.1$

in the household, e.g., through homestead gardening (Hirvonen and Heady 2018) or increased purchasing power resulting from marketing of own produce such as cash crops (Kuma et al. 2019). A recent study found that use of irrigation was associated with improved dietary diversity in Ethiopia and Tanzania (Passarelli et al. 2018). Along this line, results of this study indicate that having an irrigated plot was associated with a 4.3\% increase in household dietary diversity in rural areas, despite the fact that about only $2 \%$ of households had irrigated plots. Further, after controlling for agroecological zones and other covariates, results suggest that the fraction of agriculture within $1 \mathrm{~km}$ of residence was positively associated with household dietary diversity. Among indicators of food systems that proxy for food supply chains, we found no statistically strong relationship between household dietary diversity and distance to nearest large weekly market and distance to nearest large population center.

Clearly, results of this study indicated existing heterogeneities among rural and urban households and corresponding food systems. After controlling for state and month of interview fixed effects, results suggest that having access to mobile phone and irrigated plot, share of improved sanitation in the community, and share of land under agriculture within $1 \mathrm{~km}$ buffer were more important to rural than to urban counterparts. In contrast, having access to electricity and improved source of water for household consumption were more important to urban than rural counterparts. As noted before, while results of this study indicate the relative importance of some components of food systems to HDDS, they may not clearly show the channels through which each of these components affect HDDS. This requires additional study, which is beyond the scope of this paper. 
Despite differences in magnitude of estimated coefficients for rural and urban households, income status (being in higher expenditure quintile by comparison to those in the bottom quintile), household size, and having post-primary education by the household head were positively associated with household dietary diversity. Household dependency ratio was statistically significant on country level and only for the rural sample. After controlling for covariates, gender and age of the household head did not seem to be important correlates of HDDS (see Appendix, Table 4).

\section{Conclusions}

Existing evidence shows Nigeria is one of the countries with high levels of food and nutrition insecurity. An expanding literature emphasizes the importance of identifying entry points for interventions in the food systems as the food systems determine diet quantity, quality, diversity, and safety, which in turn determines the nutrition and health status of the population. This study attempted to contribute evidence on food group consumption patterns, HDDS, and average nutrient adequacy and their linkages with components of the food systems. Results suggest that consumption of nutrient-rich foods was low. For example, eggs and dairy products were consumed by less than $40 \%$ of households while fruits and meat were consumed by less than $60 \%$ of households, on average. In general, urban households had higher dietary diversity (mean 9.4, s.d. 1.8) than rural households (mean 8.4, s.d 1.9), and the differences are more pronounced in consumption of fruits and animal source foods. Nonetheless, rural households had higher MPA than urban households since adequacy in nutrient consumption is dependent upon not only dietary diversity but also actual quantities consumed. It should be noted here that the expenditure share of the out-of-home consumption was higher in urban households, and that the results described here are solely based on the reported in-home consumption.

Among 12 food groups, consumption of legumes, oils and fats, and vegetables was associated with $20 \%, 15 \%$, and $13 \%$ increase in household MPA, respectively. Corresponding change in MPA associated with consumption of white roots and tubers, meat, fruits, fish and other sea food, milk and milk products, and sweets was between $3 \%$ and $10 \%$. Differences in food system components may explain differences in household dietary diversity. Accordingly, results suggest that mobile phone ownership by household head, household's access to electricity, improved sources of drinking water, and percent of the community with improved sanitation were strongly associated with household dietary diversity. Disaggregation of the data by urban and rural households revealed existing heterogeneities in nutrient and dietary consumption and their associations with corresponding food systems.

Due to lack of food consumption and nutrient surveys in Nigeria, the methods used in this study substantially deviate from the recommended methodology for the estimation of nutrient and dietary gaps, and hence, results need to be treated with caution. First, in observational studies, the preferred method of data collection on food consumption is based on individual repeated 24-h recalls (Institute of Medicine (IOM) 2006). Consumption data from the LSMS-ISA is available at household level and does not reflect the intra-household distribution. Hence, individual level dietary gap analysis using these data requires assumptions regarding intrahousehold distribution of food; in this research, it was based on energy requirements of an adult non-pregnant non-lactating woman, 20-30 years, referred 
to as the AFE. However, prior research comparing the use of household consumption expenditure surveys in Bangladesh, where the division of household nutrient intake was based on the adult male equivalent, found that nutrient intakes were comparable to data obtained from combined individual 24-h recalls and foodweighing methods (Sununtnasuk and Fiedler, 2017). The aforementioned study, however, found inconsistencies in intake and adequacy status between the two methods mainly for children aged 3 years and younger. Coates et al. (2017) also found similar results based on data from Bangladesh and Ethiopia. Second, the recall period in the LSMS-ISA is 7 days, and hence, the data may suffer from recall bias, as remembering the food consumption of 1 day prior to the interview is already challenging, consumed foods could be forgotten and amounts consumed could be blurred. Also, for the HDDS results, which are normally based on 1 single recall day, this 7-day recall period will have resulted in a higher overall score, thus giving an overestimation of the HDDS. Furthermore, the amounts of food consumed by the entire household during the 1-week recall period are estimated by the respondent. This may introduce bias and could result in either under- or overestimation of the consumption. Lastly, a fixed list of foods was recalled, and the information on out-of-home consumption was limited or lacking. For households with a large portion of out-of-home consumption, the HDDS and nutrient adequacy most likely gave an underestimation of what was actually consumed. This was possibly reflected by the negative relationship between the expenditure on MAH over food at home ratio and the HDDS and MPA. However, it should be noted that the LSMS-ISA survey has a large sample size and covers all regions of Nigeria, and provides a rich source of information from the food system perspective as dietary consumption can be linked to different aspects of the food system. Also, given the long time since the last national food consumption and nutrition survey in Nigeria (2001), LSMS-ISA data could serve as a useful body of information. The results represent broadly consumption patterns of households in Nigeria and provide indicative picture of household food group and nutrient intakes, standardized to AFE. A more detailed understanding of dietary consumption patterns and their causal factors would require food consumption surveys, cutting across time and households with detailed information on food consumption by individual household members.

Given these limitations, results of this research imply that efforts aiming at improving the average nutrient adequacy in Nigeria may benefit from interventions that would improve consumption of legumes, fruits, meat, and fish regardless of whether the setting is rural or urban, and correspondingly, vegetables in urban and dairy products in rural areas. Since more diversified diets are in general beneficial to improving the average nutrient adequacy, results of this study also indicate that interventions in the food systems to improve household dietary diversity for rural and urban households may take different approaches. For rural households, stimulating agriculture through availing more agricultural land and irrigation, improving access to mobile phone, and improved sanitation seem to be promising. Whereas improving access to electricity, health services, and improved water sources seem to be more relevant to improve the diet quality of urban households. 


\section{Appendix}

\section{Construction of MPA}

Usual intake of nutrients $j$ per AFE of household $i$

$$
\mathrm{UI}_{i j}=\frac{\sum_{k}^{K} \theta_{j k} F I_{i k}}{\mathrm{AFE}_{i}}
$$

where $\theta_{j k}$ is the conversion factor of nutrient $j$ per unit of food item $k$ consumed.

$$
Z \text {-score }\left(Z_{i j}\right)=\frac{U I_{i j}-\mathrm{EAR}_{j}}{\mathrm{SD}_{j}}
$$

Probability of nutrient $j$ adequacy per nutrient of household $i\left(\mathrm{PA}_{i j}\right)$

$$
\mathrm{PA}_{i j}=f\left(Z_{i j}\right)
$$

with $f($.) being the density function of the standard normal distribution. The mean probability of nutrient adequacy (MPA) then is

$$
\mathrm{MPA}_{i}=\frac{\sum_{j=1}^{n} \mathrm{MPA}_{i j}}{n}
$$

where $n$ is the number of nutrients consumed. 
Table 3 The link between consumption of food group and household MPA

\begin{tabular}{|c|c|c|c|}
\hline & Country & Rural & Urban \\
\hline \multirow[t]{2}{*}{ Cereals } & 0.060 & $0.082^{* *}$ & -0.035 \\
\hline & $(0.036)$ & $(0.033)$ & $(0.125)$ \\
\hline \multirow[t]{2}{*}{ White roots and tubers } & $0.057^{* * *}$ & $0.062^{* * *}$ & 0.039 \\
\hline & $(0.010)$ & $(0.011)$ & $(0.025)$ \\
\hline \multirow[t]{2}{*}{ Vegetables } & $0.076^{* * *}$ & 0.054 & $0.128^{* * *}$ \\
\hline & $(0.025)$ & $(0.030)$ & $(0.045)$ \\
\hline \multirow[t]{2}{*}{ Fruits } & $0.044^{* * *}$ & $0.036^{* * *}$ & $0.060^{* * *}$ \\
\hline & $(0.007)$ & $(0.009)$ & $(0.010)$ \\
\hline \multirow[t]{2}{*}{ Meat } & $0.045^{* * *}$ & $0.044^{* * *}$ & $0.040^{* * *}$ \\
\hline & $(0.008)$ & $(0.009)$ & $(0.014)$ \\
\hline \multirow[t]{2}{*}{ Eggs } & 0.010 & 0.020 & 0.004 \\
\hline & $(0.009)$ & $(0.011)$ & $(0.012)$ \\
\hline \multirow[t]{2}{*}{ Fish and other seafood } & $0.032^{* * *}$ & $0.028^{* *}$ & $0.049^{* * *}$ \\
\hline & $(0.009)$ & $(0.011)$ & $(0.015)$ \\
\hline \multirow[t]{2}{*}{ Legumes, nuts, seeds } & $0.110^{* * *}$ & $0.101^{* * *}$ & $0.145^{* * *}$ \\
\hline & $(0.013)$ & $(0.014)$ & $(0.029)$ \\
\hline \multirow[t]{2}{*}{ Milk and milk products } & $0.027^{* * *}$ & $0.026^{* *}$ & 0.024 \\
\hline & $(0.008)$ & $(0.011)$ & $(0.014)$ \\
\hline \multirow[t]{2}{*}{ Oils and fats } & $0.083^{* * *}$ & $0.076^{* * *}$ & 0.089 \\
\hline & $(0.021)$ & $(0.024)$ & $(0.053)$ \\
\hline \multirow[t]{2}{*}{ Sweets } & $0.017^{* *}$ & 0.017 & 0.020 \\
\hline & $(0.008)$ & $(0.011)$ & $(0.014)$ \\
\hline \multirow[t]{2}{*}{ Spices, condiments, and beverages } & 0.005 & 0.018 & -0.052 \\
\hline & $(0.029)$ & $(0.032)$ & $(0.046)$ \\
\hline \multirow[t]{2}{*}{ Mobile phone $(1 / 0)$} & -0.009 & -0.014 & -0.011 \\
\hline & $(0.009)$ & $(0.009)$ & $(0.017)$ \\
\hline \multirow[t]{2}{*}{ Electricity $(1 / 0)$} & $-0.030^{* * *}$ & $-0.026^{* *}$ & -0.029 \\
\hline & $(0.009)$ & $(0.011)$ & $(0.017)$ \\
\hline \multirow[t]{2}{*}{ Improved sources of water (1/0) } & 0.007 & 0.000 & 0.009 \\
\hline & $(0.008)$ & $(0.009)$ & $(0.014)$ \\
\hline \multirow[t]{2}{*}{ Improved sanitation, community (\%) } & -0.034 & -0.022 & 0.022 \\
\hline & $(0.018)$ & $(0.017)$ & $(0.033)$ \\
\hline \multirow[t]{2}{*}{ Health center/hospital in community $(1 / 0)$} & 0.012 & 0.016 & 0.012 \\
\hline & $(0.008)$ & $(0.011)$ & $(0.010)$ \\
\hline \multirow[t]{2}{*}{ Irrigation (1/0) } & 0.014 & -0.014 & 0.099 \\
\hline & $(0.028)$ & $(0.026)$ & $(0.063)$ \\
\hline \multirow[t]{2}{*}{ Distance to nearest market (KMs) } & -0.000 & $-0.000^{* *}$ & 0.000 \\
\hline & $(0.000)$ & $(0.000)$ & $(0.000)$ \\
\hline \multirow[t]{2}{*}{ Distance in to Nearest Population Center with $+20,000$ (KMs) } & 0.000 & 0.000 & 0.000 \\
\hline & $(0.000)$ & $(0.000)$ & $(0.000)$ \\
\hline \multirow[t]{2}{*}{ Fraction of agriculture in $1 \mathrm{~km}$ buffer } & $0.000^{* *}$ & $0.001^{* *}$ & 0.000 \\
\hline & $(0.000)$ & $(0.000)$ & $(0.000)$ \\
\hline \multicolumn{4}{|l|}{ Household expenditure quintile } \\
\hline$\_2(1 / 0)$ & $0.028^{* *}$ & $0.031^{* * *}$ & 0.027 \\
\hline
\end{tabular}


Table 3 The link between consumption of food group and household MPA (Continued)

\begin{tabular}{|c|c|c|c|}
\hline & Country & Rural & Urban \\
\hline & $(0.011)$ & $(0.012)$ & $(0.028)$ \\
\hline \multirow[t]{2}{*}{$-3(1 / 0)$} & $0.071^{* * *}$ & $0.073^{* * *}$ & $0.085^{* * *}$ \\
\hline & $(0.012)$ & $(0.014)$ & $(0.030)$ \\
\hline \multirow{2}{*}{$-4(1 / 0)$} & $0.122^{* * *}$ & $0.127^{* * *}$ & $0.135^{* * *}$ \\
\hline & $(0.014)$ & $(0.017)$ & $(0.030)$ \\
\hline \multirow[t]{2}{*}{ Household expenditure quintile_5 (1/0) } & $0.215^{* * *}$ & $0.210^{* * *}$ & $0.242^{* * *}$ \\
\hline & $(0.016)$ & $(0.022)$ & $(0.031)$ \\
\hline \multirow[t]{2}{*}{ Expenditure on MAH over food at home } & -0.005 & $-0.010^{* *}$ & -0.002 \\
\hline & $(0.005)$ & $(0.004)$ & $(0.005)$ \\
\hline \multirow[t]{2}{*}{ Household size in adult female equivalent } & $-0.024^{* * *}$ & $-0.023^{* * *}$ & $-0.026^{* * *}$ \\
\hline & $(0.002)$ & $(0.002)$ & $(0.004)$ \\
\hline \multirow[t]{2}{*}{ Dependency ratio } & $0.036^{* * *}$ & 0.030 & $0.046^{* *}$ \\
\hline & $(0.012)$ & $(0.018)$ & $(0.022)$ \\
\hline \multirow[t]{2}{*}{ Male household head (1/0) } & -0.015 & -0.009 & -0.023 \\
\hline & $(0.008)$ & $(0.011)$ & $(0.013)$ \\
\hline \multirow[t]{2}{*}{ Age of household head in years } & $0.001^{* * *}$ & $0.001^{* * *}$ & $0.002^{* * *}$ \\
\hline & $(0.000)$ & $(0.000)$ & $(0.000)$ \\
\hline \multirow[t]{2}{*}{ Post-primary education of household head (1/0) } & -0.010 & -0.007 & -0.003 \\
\hline & $(0.007)$ & $(0.009)$ & $(0.013)$ \\
\hline \multirow[t]{2}{*}{ Rural } & $0.066^{* * *}$ & & \\
\hline & $(0.010)$ & & \\
\hline \multirow[t]{2}{*}{ Constant } & $-0.157^{* *}$ & -0.069 & -0.282 \\
\hline & $(0.078)$ & $(0.085)$ & $(0.173)$ \\
\hline Observations & 4023 & 2706 & 1317 \\
\hline 12 & 0.392 & 0.407 & 0.427 \\
\hline
\end{tabular}

Note: additional controls include dummies for month of interview, agroecological zone, and state of residence. Standard errors (in parentheses) clustered at level of enumeration area

${ }^{*} p<0.10,{ }^{* *} p<0.05,{ }^{* * *} p<0.01$ 
Table 4 Correlates of household dietary diversity

\begin{tabular}{|c|c|c|c|}
\hline & Country & Rural & Urban \\
\hline \multirow[t]{2}{*}{ Mobile phone (1/0) } & $0.20^{* * *}$ & $0.19^{* * *}$ & 0.24 \\
\hline & $(0.06)$ & $(0.06)$ & $(0.15)$ \\
\hline \multirow[t]{2}{*}{ Electricity $(1 / 0)$} & $0.13^{* *}$ & 0.12 & $0.20^{*}$ \\
\hline & $(0.06)$ & $(0.07)$ & $(0.12)$ \\
\hline \multirow[t]{2}{*}{ Improved sources of water (1/0) } & $0.12^{*}$ & 0.06 & $0.24^{* *}$ \\
\hline & $(0.06)$ & $(0.07)$ & $(0.10)$ \\
\hline \multirow[t]{2}{*}{ Improved sanitation, community (\%) } & $0.23^{* *}$ & $0.33^{* * *}$ & 0.02 \\
\hline & $(0.10)$ & $(0.11)$ & $(0.16)$ \\
\hline \multirow[t]{2}{*}{ Health center/hospital in community $(1 / 0)$} & $-0.11^{* *}$ & -0.08 & $-0.15^{* *}$ \\
\hline & $(0.05)$ & $(0.07)$ & $(0.07)$ \\
\hline \multirow[t]{2}{*}{ Irrigation (1/0) } & 0.17 & $0.36^{*}$ & -0.31 \\
\hline & $(0.20)$ & $(0.20)$ & $(0.28)$ \\
\hline \multirow[t]{2}{*}{ Distance to nearest market (KMs) } & 0.00 & 0.00 & 0.00 \\
\hline & $(0.00)$ & $(0.00)$ & $(0.00)$ \\
\hline \multirow[t]{2}{*}{ Distance in to Nearest Population Center with $+20,000$ (KMs) } & 0.00 & -0.00 & 0.00 \\
\hline & $(0.00)$ & $(0.00)$ & $(0.00)$ \\
\hline \multirow[t]{2}{*}{ Fraction of agriculture in $1 \mathrm{~km}$ buffer } & $0.00^{*}$ & $0.00^{*}$ & 0.00 \\
\hline & $(0.00)$ & $(0.00)$ & $(0.00)$ \\
\hline \multicolumn{4}{|l|}{ Household expenditure quintile } \\
\hline \multirow[t]{2}{*}{$2(1 / 0)$} & $0.88^{* * *}$ & $0.90^{* * *}$ & $0.87^{* * *}$ \\
\hline & $(0.07)$ & $(0.07)$ & $(0.19)$ \\
\hline \multirow[t]{2}{*}{$-3(1 / 0)$} & $1.38^{* * *}$ & $1.41^{* * *}$ & $1.31^{* * *}$ \\
\hline & $(0.08)$ & $(0.09)$ & $(0.20)$ \\
\hline \multirow[t]{2}{*}{$-4(1 / 0)$} & $1.84^{* * *}$ & $1.86^{* * *}$ & $1.80^{* * *}$ \\
\hline & $(0.11)$ & $(0.10)$ & $(0.24)$ \\
\hline \multirow[t]{2}{*}{ Household expenditure quintile_5 (1/0) } & $2.25^{* * *}$ & $2.18^{* * *}$ & $2.27^{* * *}$ \\
\hline & $(0.12)$ & $(0.13)$ & $(0.25)$ \\
\hline \multirow[t]{2}{*}{ Household size in adult female equivalent } & $0.15^{* * *}$ & $0.14^{* * *}$ & $0.16^{* * *}$ \\
\hline & $(0.01)$ & $(0.01)$ & $(0.02)$ \\
\hline \multirow[t]{2}{*}{ Dependency ratio } & $0.23^{* *}$ & $0.31^{* *}$ & 0.15 \\
\hline & $(0.11)$ & $(0.13)$ & $(0.17)$ \\
\hline \multirow[t]{2}{*}{ Male household head $(1 / 0)$} & 0.00 & 0.01 & -0.02 \\
\hline & $(0.06)$ & $(0.08)$ & $(0.11)$ \\
\hline \multirow[t]{2}{*}{ Age of household head in years } & -0.00 & -0.00 & -0.00 \\
\hline & $(0.00)$ & $(0.00)$ & $(0.00)$ \\
\hline \multirow[t]{2}{*}{ Post-primary education of household head $(1 / 0)$} & $0.22^{* * *}$ & $0.21^{* * *}$ & $0.22^{* *}$ \\
\hline & $(0.06)$ & $(0.08)$ & $(0.09)$ \\
\hline \multirow[t]{2}{*}{ Rural } & -0.08 & & \\
\hline & $(0.07)$ & & \\
\hline \multirow[t]{2}{*}{ Cons } & $6.91^{* * *}$ & $6.77^{* * *}$ & $7.21^{* * *}$ \\
\hline & $(0.31)$ & $(0.32)$ & $(0.62)$ \\
\hline$N$ & 4040 & 2721 & 1319 \\
\hline$r^{2}$ & 0.50 & 0.52 & 0.38 \\
\hline
\end{tabular}

Note: additional controls include dummies for month of interview, agroecological zone, and state of residence. Standard errors (in parentheses) clustered at level of enumeration area

${ }^{*} p<0.10,{ }^{* *} p<0.05,{ }^{* * *} p<0.01$ 


\section{Acknowledgements}

Not applicable

\section{Authors' contributions}

$I B, R R$, TA, ET, and DM originated the idea; DM, LT, IB, and ET developed methodology for data analysis. $L T$ identified food composition tables; DM analyzed the data and wrote the first draft. LT, GK, and VL proofread the draft and modified technical aspects. All authors improved the discussion of results and write-up of the manuscript. All authors read and approved the final manuscript.

\section{Declaration}

\section{Competing interests}

The authors declare that they have no competing interests.

\section{Author details}

${ }^{1}$ Wageningen Economic Research, Wageningen University and Research, Pr. Beatrixlaan 582, 2595, BM, The Hague, The Netherlands. ${ }^{2}$ Division of Human Nutrition and Health, Wageningen University and Research, P.O. Box 17, 6700, AA, Wageningen, The Netherlands. ${ }^{3}$ Advancing Nutrition, USAID, ArlingtonVA 22202USA. ${ }^{4}$ Wageningen Economic Research, Wageningen University \& Research, Pr. Beatrixlaan 582, 2595, BM, The Hague, The Netherlands.

Received: 16 September 2019 Revised: 5 February 2020

Accepted: 26 March 2021 Published online: 08 June 2021

\section{References}

Adegboye OR, Smith C, Anang D, Musa H (2016) Comparing and contrasting three cultural food customs from Nigeria and analyzing the nutrient content of diets from these cultures with the aim of proffering nutritional intervention. Crit Rev Food Sci Nutr 56:2483-2494. https://doi.org/10.1080/10408398.2013.862201

Akerele D (2015) Household food expenditure patterns, food nutrient consumption and nutritional vulnerability in Nigeria: implications for policy. Ecol Food Nutr 54(5):546-571

Akerele D, Sanusi RA, Fadare OA, Ashaolu OF (2017) Factors influencing nutritional adequacy among rural households in Nigeria: how does dietary diversity stand among influencers? Ecol Food Nutr 56(2):187-203

Aliyu AA, Amadu L. (2017). Urbanization, cities, and health: The challenges to Nigeria - A review. Ann Afr Med 16:149-158

Babatunde RO, Qaim M (2010) Impact of off-farm income on food security and nutrition in Nigeria. Food Policy 35(4):303311. https://doi.org/10.1016/j.foodpol.2010.01.006

Barnett I, Scott N, Batchelor S, Haddad L (2016) Dial 'N' for nutrition? A landscape analysis of what we know about mnutrition, $\mathrm{m}$-agriculture and m-development. IDS Working Paper 481. Institute of Development Studies, Brighton, ISSN: 2040-0209 ISBN: 978-1-78118-342-7

Coates J, Rogers BL, Blau, A, Lauer J, Rob A. (2017). Filling a dietary data gap? Validation of the adult male equivalent method of estimating individual nutrient intakes from household-level data in Ethiopia and Bangladesh. Food Policy 72:27-42.

de Brauw A, Herskowitz S (2018) Income variability, evolving diets, and demand for processed foods in Nigeria. IFPRI Discussion Paper 01793. International Food Policy Research Institute, Washington, DC

De Moura FF, Moursi M, Lubowa A, Ha B, Boy E et al (2016) Cassava intake and vitamin A status among women and preschool children in Akwa-lbom, Nigeria. PLoS One 10(6):1-14

Development Initiatives (2017) Global nutrition report 2017: nourishing the SDGs. Development Initiatives, Bristol

Ecker O, Hatzenbuehler PL, Mahrt K (2018) Transforming agriculture for improving food and nutrition security among Nigerian farm households. IFPRI Nigeria Strategy Support Program, Working Paper 56. International Food Policy Research Institute, Washington, DC

European Food Safety Authority (EFSA). (2017). Dietary reference values for nutrients: Summary report. EFSA supporting publication, 2017(e15121):98 https://doi.org/10.2903/sp.efsa.2017.e15121

FAO, IFAD, UNICEF, WFP, \& WHO (2017) The state of food security and nutrition in the world 2017. Building resislience for peace and food security. FAO, Rome

Heady D, Alderman H (2019) The relative caloric prices of healthy and unhealthy foods differ systematically across income levels and continents. J Nutr. https://doi.org/10.1093/jn/nxz158

Heady D, Hirvonen K, Hoddinott J (2018) Animal sourced foods and child stunting. Amer J Agr Econ 100(5):1302-1319. https://doi.org/10.1093/ajae/aay053

Herforth A, Ahmed S (2015) The food environment, its effects on dietary consumption, and potential for measurement within agriculture-nutrition interventions. Food Sec 7:505-520

Hirvonen K (2016) Rural-urban differences in children's dietary diversity in Ethiopia: a Poisson decomposition analysis. Econ Lett 147:12-15

Hirvonen K, Heady D (2018) Can governments promote homestead gardening at scale? Evidence from Ethiopia. Global Food Sec 19:40-47

Hirvonen K, Hoddinott J, Minten B, Stifel D (2017) Children's diets, nutrition knowledge, and access to markets. World Dev 95: 303-315

HLPE (2017) Nutrition and food systems. A report by the High Level Panel of Experts on Food Security and Nutrition of the Committee on World Food Security, Rome. http://www.fao.org/3/i7846e/i7846e.pdf

Institute of Medicine (IOM) (2006) In: Otten JJ, Hellwig JP, Meyers LD (eds) Dietary reference intakes: the essential guide to nutrient requirements. National Academies Press, Washington, D.C

Kandala NB, Emina JBO (2016) The dual burden of nutrition transition among women in Sub-Saharan Africa: a case study of underweight in Nigeria. J Biosocial Sc 48(4):486-501. https://doi.org/10.1017/S0021932015000334

Kandala NB, Stranges S (2014) Geographic variation of overweight and obesity among women in Nigeria: a case for nutritional transition in Sub-Saharan Africa. PLoS One 9(6):1-11 
Kengne AP et al (2017) Trends in obesity and diabetes across Africa from 1980 to 2014: an analysis of pooled populationbased studies. Int J Epidemiol: 46(5):1421-1432. https://doi.org/10.1093/ije/dyx078

Kuma T, Dereje M, Hirvonen K, Minten B (2019) Cash crops and food security: evidence from Ethiopian smallholder coffee producers. J Dev Stud 55(6):1267-1284

Langenhoven ML, Conradie PJ, Wolmarans P, Faber M (1991) MRC food quantities manual. In: South African Medical Research Council. Parow: iv + 213 pp (English) - Update in progress, 2nd edn

Mohiddin L, Phelps L, Walters T (2012) Urban malnutrition: a review of food security and nutrition among the urban poor. Nutrition Works: International Public Nutrition Resource Group, pp 1-56 Retrieved from http://www.fao.org/fileadmin/ user_upload/drought/docs/NutritionWorkdsUrbanmalnutrition 201307.pdf

Nigerian National Bureau of Statistics (NBS), the Federal Ministry of Agriculture and Rural Development, and the World Bank (2016) LSMS-Integrated Surveys on Agriculture General Household Survey Panel 2015/16. A report.

Passarelli S, Mekonnen D, Bryan E, Ringler C (2018) Evaluating the pathways from small-scale irrigation to dietary diversity: evidence from Ethiopia and Tanzania. Food Sec 10:981-997

Popkin BM (1993) Nutritional patterns and transitions. Popul Dev Rev 1(19):138-157

Popkin BM (2015) Nutrition transition and the global diabetes epidemic. Curr Diab Rep 15(9):64. https://doi.org/10.1007/s11 892-015-0631-4

Ruel MT (2003) Operationalizing dietary diversity: a review of measurement issues and research priorities. J Nutr 133:3911S39265

Ruel MT (2019) New evidence on nutrition-sensitive agricultural programs. In: Fan et al (eds) Agriculture for improved nutrition - seizing the momentum. IFPRI and CAB International, Wallingford, UK

Ruel MT, Quisumbing A, Balagamwala M (2018) Nutrition-sensitive agriculture: what have we learned so far? Global Food Sec 17:128-153

Sibhatu KT, Qaim M (2018) Review: Meta-analysis of the association between production diversity, diets, and nutrition in smallholder farm households. Food Policy 77:1-18

Spears D (2013) How much international variation in child height can sanitation explain? Policy Research Working Paper Series 6351. The World Bank, Washington, DC

Stifel DD, Minten B (2017) Market access, well-being, and nutrition: evidence from Ethiopia. World Dev 90:229-241

Sununtnasuk C, Fiedler, JL (2017). Can household-based food consumption surveys be used to make inferences about nutrient intakes and inadequacies? A Bangladesh case study. Food Policy 72:121-131.

Swindale A, Bilinsky P (2006) Household dietary diversity score (HDDS) for measurement of household food access: Indicator Guide. VERSION 2. FANTA, Washington, DC

Thompson B, Amoroso L (2014) Improving diets and nutrition food-based approaches. The Food and Agriculture Organization of the United Nations and CABI, Rome

US Department of Agriculture, Agricultural Research Service (USDA) (2016) Nutrient data laboratory. USDA National Nutrient Database for Standard Reference, Release 28 (Slightly revised). Version Current: May 2016, Maryland

US Department of Agriculture, Agricultural Research Service (USDA) Nutrient Data Lab (2017) USDA Table of Nutrient Retention Factors, Release 6 (2007). USDA Agricultural Research Service, Maryland, https://doi.org/10.15482/USDA.ADC/14 09034

Voortman T, Kiefte-de Jong JC, Ikram MA, Stricker BH, van Rooij FJA, Lahousse L, Tiemeier H et al (2017) Adherence to the 2015 Dutch dietary guidelines and risk of non-communicable diseases and mortality in the Rotterdam Study. Eur J Epidemiol 32:993-1005

West CE, Pepping F, Scholte I, Jansen W, Albers HFF (1989) Tanzania food composition table for energy and eight important nutrients in foods commonly eaten in East Africa. Technical Centre for Agriculture and Rural Cooperation (CTA) of ACP/ ECP, Ede

Wiesmann D, Arimond M, Loechl C (2009) Dietary diversity as a measure of the micronutrient adequacy of women's diets: results from rural Mozambique site, vol 360. Food and Nutrition Technical Assistance II Project, FHI, Washington, DC

World Health Organization and Food and Agriculture Organization of the United Nations (WHO/FAO) (2004) Vitamin and mineral requirements in human nutrition. In: Report of a joint FAO/WHO expert consultation, Bangkok, Thailand, 21-30 September 1998, 2nd edn

\section{Publisher's Note}

Springer Nature remains neutral with regard to jurisdictional claims in published maps and institutional affiliations.

\section{Submit your manuscript to a SpringerOpen ${ }^{\circ}$ journal and benefit from:}

- Convenient online submission

- Rigorous peer review

- Open access: articles freely available online

High visibility within the field

- Retaining the copyright to your article

Submit your next manuscript at $\boldsymbol{s p r i n g e r o p e n . c o m ~}$ 